\title{
HUBUNGAN ANTARA SELF CONTROL DAN STRES KERJA DENGAN AGRESIVITAS POLISI
}

\author{
Andra Purnama Putra ${ }^{1}$, Rr. Amanda Pasca Rini ${ }^{2}$, Sahat Saragih ${ }^{3}$ \\ Magister Psikologi Profesi \\ ${ }^{1,2,3}$ Fakultas Psikologi Universitas 17 Agustus 1945 Surabaya, Surabaya, Jawa \\ Timur, Indonesia
}

\begin{abstract}
Aggression is a behavior that is intentionally to hurt,threaten, or endanger others or another object physically or verbal and direct or indirect. Aggression is a common characteristic that can't be erase from human life, especially police. All police has it own aggression, but the capacity is different with others police depend on self control and work stress they have. The research purpose's to know correlation of self control (X1) and work stress (X2) with police aggression (Y). It subject is sergeant policeman in Sidoarjo. Subject amount 120 Police. The sampel taken by purposive sampling method. Statistical analysis method that be used is regression and using SPSS 22.00 for windows. the first result is there is correlation between self control, work stress and Police aggression.the second result is there is correlation negatively between self control and aggression. The third result is there is correlation positively between work stress and aggression.
\end{abstract}

Keywords : Self Control, Aggression, Work Stress, Police

\begin{abstract}
ABSTRAK
Agresivitas adalah suatu perilaku yang dengan sengaja dilakukan untuk menyakiti, mengancam, atau membahayakan individu atau objek yang menjadi sasaran perilaku tersebut baik secara fisik atau verbal dan langsung atau tidak langsung. Agresivitas merupakan suatu sifat yang tidak dapat lepas dari kehidupan manusia, termasuk Polisi. Setiap Polisi memiliki agresivitas yang berbeda tergantung self control dan stres kerja yang dimiliki. Penelitian ini menguji hubungan antara self control dan stres kerja dengan agresivitas Polisi. Populasi penelitian adalah 120 orang Bintara Polisi di Polresta Sidoarjo. Hasil penelitian yang pertama menyatakan ada hubungan yang signifikan antara self control dan stres kerja dengan agresivitas Polisi dengan $\mathrm{R}=0.487$ dan $\mathrm{F}=55.543$. Hasil penelitian kedua didapat nilai Koefisien korelasi agresivitas dengan self control adalah -0.496 dengan $\mathrm{p}=0.00$ artinya ada hubungan negatif self control dengan agresivitas. Hasil penelitian ketiga didapat nilai koefisien korelasi agresivitas dengan stres kerja adalah 0.608 dengan $\mathrm{p}=0.00$ artinya ada hubungan positif stres kerja dengan agresivitas.
\end{abstract}

Kata Kunci : Self Control, Stres Kerja, Agresivitas, Polisi 


\section{PENDAHULUAN}

Stress dapat terjadi pada siapa saja dan kapan saja. Stress tidak hanya dapat berdampak positif tetapi juga negatif. Jika stress berdampak negatif pada individu yang seharihari berhubungan dengan masyrakat dan bekerja dengan menggunakan kekuatan wewenang kekuasaan seperti Polisi, maka hal tersebut dapat mengakibatkan sesuatu yang buruk terjadi, seperti salah satunya penyalahgunaan wewenang. Lingkungan kerja Polisi memiliki kemungkinan tinggi mengalami halhal yang menakutkan, mengejutkan dan mengakibatkan trauma psikologis sehingga dapat menimbulkan terjadinya stress dan terjadi perubahan dalam kepribadian seseorang dari pengalaman yang dialaminya. Stresor pada Polisi dapat dikarenakan oleh beberapa faktor termasuk organisasi dan kondisi pekerjaan (Indri, 2010).

Sesuai dengan Undang - undang nomor 2 tahun 2002 tentang Kepolisian Negara Republik Indonesia khususnya Bab III pasal 13 menjelaskan bahwa Polisi memiliki tugas dan wewenang sebagai pelindung, pelayan dan pengayom masyarakat. Namun di sisi lain anggota polisi juga wajib bersikap tegas terhadap individu yang melanggar hukum dan mengancam keamanan serta ketertiban. Sering kali dengan alasan menjaga keamanan dan ketertiban, Polisi menggunakan kekerasan fisik maupun psikis terhadap masyarakat sipil baik dalam penanganan kasuskasus kejahatan maupun kasus nonkejahatan (seperti; demonstrasi, sengketa tanah, pelanggaran lalu lintas, dan lain sebagainya).

Media informasi, cetak maupun elektronik akhir-akhir ini juga sering menyoroti kasus-kasus "oknum" polisi yang melakukan tindak kejahatan seperti, seorang anggota Polri yang menembak atasannya, Polisi yang menembak istrinya dan lain sebagainya. Pada tahun 2006, Komisi Untuk Orang Hilang dan Korban Tindak Kekerasan mencatat terdapat 92 kasus yang melibatkan anggota kepolisian. diantaranya adalah 36 kasus penganiayaan dan 18 kasus penembakan serta 26 kasus 
penembakan terhadap pelaku kriminal (Mukarromah, dalam jurnal psikologi 2008). Hal serupa juga diberitakan media, seorang oknum Brimob (Brigade Mobile) Polda Jatim menembak rahang mahasiswa salah satu universitas di Jember hingga tewas. Kejadian tersebut berawal dari percekcokan antara oknum Brimob dengan mahasiswa yang akhirnya terjadilah perkelahian dan berujung pada tertembaknya mahasiswa tersebut (http://www.tribunnews.com/regiona 1/2017/03/14, diakses 4 April 2017).

Perilaku yang merugikan atau menimbulkan korban pada pihak lain dalam uraian diatas dapat digolongkan sebagai perilaku agresif (Sarwono, 2002). Setidaknya terdapat beberapa faktor munculnya agresivitas, antara lain : 1. Faktor frustasi, yaitu kondisi dimana individu mengalami hambatan atau gagal dalam mencapai tujuannya (Baron dan Byrne, 2005; Sears dan kawan-kawan, 1991); 2. Provokasi, merupakan aktivitas menghina atau mengancam keselamatan individu (Baron dan Byrne, 2005); 3. Efek senjata, individu yang bersenjata cenderung lebih agresif dari pada individu yang tidak bersenjata (Krahe, 2005); 4. Kekerasan di media, intensitas menonton adegan kekerasan di televisi meningkatkan kecenderungan agresivitas (Baron dan Byrne, 2005; Sears dan kawankawan, 1991); 5. Alkohol dan obatobatan, individu yang mengonsumsi alkohol secara berlebihan cenderung bertindak agresif (Baron dan Byrne, 2005); 6. Temperatur, suhu lingkungan yang tinggi berpengaruh pada perilaku sosial berupa peningkatan agresivitas (Baron dan Byrne, 2005); 7. Kesesakan, meningkatkan kemungkinan berperilaku agresif jika diiringi perasaan jengkel dan frustasi (Krahe, 2005); 8. Polusi udara, memicu agresivitas terutama jika individu merasa tidak nyaman karenanya (Baron dan Byrne, 2005; Berkowitz, 1995); 9. Kebisingan, dalam kapasitasnya sebagai pengintensif perilaku agresif yang sedang berlangsung, kebisingan menguatkan kecenderungan perilaku agresi (Krahe, 2005); 10. Kepribadian, mempengaruhi cara individu dalam bereaksi, berfikir, merasa, 
berinteraksi dan beradaptasi dengan lingkungan sekitar (Baron dan Byrne, 2005); 11. Hormon, hormone testosterone memiliki pengaruh terhadap agresivitas (Sarwono, 2002); 12. Gender, pria cenderung memiliki agresivitas yg lebih tinggi dibandingkan wanita (Baron dan Byrne, 2005); dan 13. Harga diri, semakin tinggi harga diri membuat kecenderungan agresivitas meningkat (Sarwono, 2002).

Seharusnya, Polisi harus dapat mengontrol dirinya agar tidak mudah terprovokasi karena pada saat seleksi menjadi anggota polisi, setiap anggota polisi dipastikan melewati serangkaian tes kepribadian, kematangan emosi dan sebagainya. Menurut Ghufron (2004), setiap individu memiliki kontrol diri untuk mengatur dan mengarahkan perilakunya. Sebagai salah satu sifat kepribadian kontrol diri pada satu individu dengan individu lain tidaklah sama. Ada yang memiliki kontrol diri yang tinggi dan ada individu yang memiliki kontrol diri yang rendah. Kontrol diri dapat diartikan sebagai suatu aktivitas pengendalian tingkah laku, pengendalian tingkah laku mengandung makna yaitu melakukan pertimbangan-pertimbangan terlebih dahulu sebelum memutuskan sesuatu untuk bertindak. Semakin intens pengendalian tingkah laku, semakin tinggi pula kontrol diri seseorang.

Tangney, Baumeister, dan Boone (2004) menyebutkan 5 aspek self control antara lain : 1. Selfdiscipline, yaitu kemampuan individu untuk fokus pada disiplin dirinya. Individu dengan selfdiscipline mampu menahan diri dan memiliki konsentrasi yang baik; 2. Deliberate/nonimpulsive, yaitu kemampuan individu untuk bersifat hati-hati dan tidak tergesa-gesa dalam mangambil keputusan dan melakukan sesuatu; 3. Healthy habits, yaitu kemampuan memilih dan memilah perilaku-perilaku yang bersifat positif bagi dirinya; 4. work ethic kemampuan individu agar tidak mudah terpengaruh dan fokus pada pekerjaannya; 5. Reliability, yaitu kemampuan individu dalam pelaksanaan rancangan jangka panjang secara konsisten untuk pencapaian tertentu. 
Dari penjelasan tersebut dapat dikatakan, bahwa kemampuan mengontrol diri memungkinkan seseorang untuk berperilaku lebih terarah dan dapat menyalurkan dorongan dari dalam dirinya agar tidak menyimpang dari norma dan aturan yang berlaku di masyarakat. Dalam kaitannya dengan anggota polisi, kemampuan mengontrol diri dapat membantu anggota polisi mengendalikan diri dan mengatur perilakunya sehingga mencegah mereka dari perbuatan menyimpang seperti bertindak agresif. Jadi, untuk dapat mengatasi masalahnya, salah satu kunci pokoknya adalah anggota polisi harus belajar mengontrol diri terhadap perilaku yang dapat mengarah pada konsekuensi negatif serta belajar mengendalikan emosi dalam dirinya.

Berdasarkan uraian diatas maka, perumusan masalah yang diajukan adalah apakah terdapat hubungan antara self control dan stress kerja dengan agresivitas Polisi, menganalisa hubungan antara self control dengan agresivitas Polisi, dan menganalisa hubungan antara stres kerja dengan agresivitas Polisi.
Manfaat penelitian ini untuk memberikan kontribusi mengenai pembahasan tentang agresivitas Polisi sehingga menjadi informasi yang berguna bagi Instansi Kepolisian Republik Indonesia.

\section{Agresivitas}

Agresivitas merupakan suatu perilaku yang sengaja dilakukan untuk menyakiti, mengancam, atau membahayakan individu atau objek yang menjadi sasaran perilaku tersebut baik secara fisik atau verbal dan langsung atau tidak langsung (Myers, 2005; Berkowitz, 2003; Buss, 1992).

Mengacu pada teori Buss (1992), ciri-ciri agresivitas antara lain antara lain adalah perilaku agresi secara fisik atau verbal, secara aktif atau pasif, dan secara langsung atau tidak langsung. Tiga klasifikasi tersebut masing-masing akan saling berinteraksi, sehingga menghasilkan delapan bentuk perilaku agresi, yaitu : a. Agresi fisik aktif langsung, seperti memukul, menembak atau menusuk orang lain; b. Agresi fisik tidak langsung, seperti membuat jebakan untuk mencelakakan orang lain; c. Agresi fisik pasif langsung, 
seperti tidak mau memberikan jalan kepada orang lain; d. Agresi fisik pasif tidak langsung, seperti menolak untuk melakukan sesuatu atau perintah orang lain; e. Agresi verbal aktif langsung, seperti mencaci maki orang lain; f. Agresi verbal aktif tidak langsung, seperti menyebarkan berita gossip tentang orang lain; g. Agresi verbal pasif langsung, seperti tidak setuju dengan pendapat orang lain, tapi tidak mau mengatakannya atau tidak mau menjawab pertanyaan orang lain; dan h. Agresi verbal pasif tidak langsung, seperti menolak untuk berbicara dengan orang lain. Ciri-ciri dari agresivitas tersebut akan dijadikan acuan skala agresivitas pada penelitian ini.

\section{Self Control}

Self control merupakan kemampuan individu untuk mengendalikan dan menguasai perilaku, menunda pemuasan segera untuk mempengaruhi hasil dari lingkungannya (Chaplin, 2005). Hal tersebut selaras dengan pendapat yang dikemukakan Goldfried dan Merbaum (dalam Fasilita, 2012) menyebutkan self control sebagai suatu kemampuan untuk menyusun, membimbing, mengatur dan mengarahkan perilaku individu kearah konsekuensi yang positif.

Tangney, Baumeister, dan Boone (2004) menyebutkan 5 aspek self control antara lain : 1. Selfdiscipline, yaitu kemampuan individu untuk fokus pada disiplin dirinya. Individu dengan selfdiscipline mampu menahan diri dan memiliki konsentrasi yang baik; 2 . Deliberate/nonimpulsive, yaitu kemampuan individu untuk bersifat hati-hati dan tidak tergesa-gesa dalam mangambil keputusan dan melakukan sesuatu; 3. Healthy habits, yaitu kemampuan memilih dan memilah perilaku-perilaku yang bersifat positif bagi dirinya; 4. work ethic kemampuan individu agar tidak mudah terpengaruh dan fokus pada pekerjaannya; 5. Reliability, yaitu kemampuan individu dalam pelaksanaan rancangan jangka panjang secara konsisten untuk pencapaian tertentu. Ciri-ciri self control tersebut akan dijadikan acuan skala self control pada penelitian ini.

\section{Stres Kerja}

Stres kerja merupakan respon yang timbul terhadap stresor pada 
pekerjaan yang menyebabkan seseorang tidak berfungsi optimal (Karimi dan Alipour, 2011; Bisen dan Priya, 2010; Munandar, 2006; Alves, 2005).

Menurut Bisen dan Priya (2010), gejala stress pada individu dapat dilihat dari beberapa ciri antara lain : a. Gejala fisik, seperti pusing, sakit leher, nyeri punggung, gangguan perut, peningkatan detak jantung, perubahan selera makan, ketegangan pada otot dan tidur tidak teratur, dsb; b. Gejala emosional, seperti depresi, sensitive, mudah marah, cemas, adanya pikiran untuk bunuh diri, perasaan tidak berdaya, dsb; dan c. Gejala perilaku, seperti menggigit jari, penggunaan rokok meningkat, mengetuk jari, kehilangan minat pada penampilan fisik, menarik diri dari interaksi dengan orang lain, dan peningkatan penggunaan alkohol atau resep obat, dsb. Ciri-ciri stres kerja tersebut akan dijadikan acuan skala stres kerja pada penelitian ini.

\section{Hipotesis}

Hipotesis dalam penelitian ini yaitu :
1. Ada hubungan yang signifikan antara Self Control dan Stres Kerja dengan Agresivitas.

2. Ada hubungan negatif Self Control dengan Agresivitas.

3. Ada hubungan positif Stres kerja dengan Agresivitas.

\section{METODE PENELITIAN}

Teknik pengambilan sampel dalam penelitian ini menggunakan teknik purposive sampling yaitu 120 orang anggota Polisi berpangkat Bintara yaitu yang berusia 20 tahun sampai 55 tahun yang didasari karena Polisi berpangkat Bintara lebih banyak menghabiskan tugasnya berhadapan langsung dengan masyarakat. Serta berjenis kelamin laki-laki karena menurut teori, Individu dengan jenis kelamin lakilaki cenderung bersikap agresi daripada wanita.

Alat ukur yang digunakan dalam penelitian ini adalah skala. Ada tiga skala yang digunakan dalam penelitian ini yaitu skala agresivitas dengan indikator antara lain : 1 . Agresi fisik aktif langsung; 2. Agresi fisik aktif tidak langsung; 3. Agresi 
fisik pasif langsung; 4. Agresi fisik pasif tidak langsung; 5. Agresi verbal aktif langsung; 6. Agresi verbal aktif tidak langsung; 7. Agresi verbal pasif langsung; dan 8. Agresi verbal pasif tidak langsung. Sedangkan skala self control dengan indikator antara lain : 1. Self-discipline; 2 . Deliberate/nonimpulsive; 3. Healthy habits; 4. Work ethic; dan 5. Reliability. Dan skala stres kerja dengan indikator antara lain : 1 . Gejala fisik; 2. Gejala emosional; dan 3. Gejala perilaku.

Untuk perhitungannya menggunakan teknik analisis regresi ganda yang diolah dengan program Statistic Package for Social Science for windows (SPSS) versi 22.0.

\section{HASIL DAN PEMBAHASAN}

Data yang diperoleh selanjutnya dianalisis dengan menggunakan teknik analisis regresi. Untuk membuktikan hipotesis bahwa ada hubungan antara self control dan stres kerja dengan agresivitas. Data yang diperoleh dianalisis dan menunjukkan nilai korelasi ganda $\mathrm{R}$ sebesar 0.487 dan nilai $F=55.543$ dengan $\mathrm{p}=0.000$. nilai $\mathrm{p}<0.05$ menyatakan bahwa ada hubungan yang signifikan antara self control dan stres kerja dengan agresivitas Polisi. Dengan demikian, hipotesis penelitian pertama diterima.

Untuk membuktikan hipotesis bahwa ada hubungan negatif Self Control dengan Agresivitas. Koefisien korelasi antara Agresivitas dengan Self Control adalah -0.496 dengan $\mathrm{p}=0,00$, yang berarti hubungan kedua variabel adalah signifikan. Dengan demikian, hipotesis penelitian kedua diterima.

Untuk membuktikan hipotesis bahwa ada hubungan positif Stres Kerja dengan Agresivitas. Koefisien korelasi antara Agresivitas dengan Stres Kerja adalah 0.608 dengan $\mathrm{p}=$ 0,00 , yang berarti hubungan kedua variabel adalah signifikan. Dengan demikian, hipotesis penelitian ketiga juga diterima.

Penelitian ini membuktikan ada hubungan antara self control dan stres kerja dengan agresivitas secara signifikan. Agresivitas merupakan suatu perilaku yang dengan sengaja dilakukan untuk menyakiti, mengancam, atau membahayakan individu atau objek-objek yang menjadi sasaran perilaku tersebut 
baik secara fisik atau verbal dan langsung atau tidak langsung. Sebagai pelindung, pengayom dan pelayan masyarakat, seharusnya Polisi harus dapat mengontrol sikap agresivitas yang dimiliki, karena pada dasarnya Polisi merupakan sipil yang dipersenjatai, bukan lagi militer. Polisi harus mampu mengurangi kecenderungan agresivitas yang dimiliki dengan cara meningkatkan self control dan mengurangi stres kerja yang dimiliki Polisi. Self control merupakan kemampuan individu untuk dapat mengendalikan atau menguasai tingkah laku, menunda pemuasaan segera untuk mempengaruhi hasil dari lingkungannya. Polisi yang memiliki self control yang baik cenderung mampu mengurangi kecenderungan agresivitasnya. Sedangkan stres kerja merupakan respon fisik, emosional, maupun perilaku terhadap stresor pada pekerjaan yang menyebabkan seseorang tidak berfungsi optimal. Polisi yang memiliki stres kerja yang tinggi cenderung memiliki tingkat agresivitas yang tinggi pula. Jadi, hipotesis kedua yang menyatakan ada hubungan yang signifikan antara self control dan stres kerja dengan agresivitas diterima.

\section{KESIMPULAN}

Penelitian ini dilakukan pada Polisi laki-laki berpangkat Bintara di Polresta Sidoarjo dengan jumlah subjek penelitian sebanyak 120 orang. Analisis data dilakukan dengan menggunakan teknik regresi. Hasilnya menunjukkan bahwa hipotesis pertama terbukti yaitu ada hubungan antara self control dan stres kerja dengan agresivitas secara signifikan, hipotesis kedua diterima yaitu ada hubungan negatif yang signifikan antara self control dengan agresivitas dan hipotesis ketiga juga diterima yaitu ada hubungan positif yang signifikan antara stres kerja dengan agresivitas Polisi.

\section{DAFTAR PUSTAKA}

Alves, S. (2005). A study of occupational stress, scope of practice, and collaboration in nurse anesthetists practicing in anesthesia care team settings. AANA Journal, vol 73. No 6, pg. 443. 
Arikunto, S. (2006). Prosedur Penelitian : Suatu Pendekatan Praktik. Edisi ke tujuh. Jakarta : Rineka Cipta.

Aulya, D. (2013). Faktor-Faktor Yang Berhubungan Dengan Stres Kerja Pada Polisi Lalu Lintas Di Polres Metro Jakarta Pusat. Skripsi, tidak diterbitkan. Jakarta : Universitas Islam Negeri Syarif Hidayatullah.

Baron, R.A., \& Byrne, D. (2005). Psikologi sosial. Edisi ke sepuluh. Jakarta: Erlangga.

Berkowitz, L. (2003). Agresi 1, sebab dan akibatnya. Jakarta: Pustaka Binaman Pressindo.

Bisen, V. \& Priya. (2010). Industrial Psychology. New Delhi : New Age International Publisher.

Buss, A.H \& Perry, M. (1992). "Personality Process and Individual Differences: The Aggression Questionnaire. Journal of Personality and Social Psychology". The American Psychologycal Association Inc. Vol. 63. No. 3. 452-459. Pdf.

Calhoun, J.F. (1990). Psychology Of Adjustment \& Human Relationship. New York: Mc Graw Hill.
Chaplin, J.P. (2005). Kamus Lengkap Psikologi. Alih bahasa : Kartini Kartono. Jakarta: PT Raja Grafindo Persada.

Fasilita, D.A. (2012). Kontrol Diri terhadap Perilaku Agresif Ditinjau dari Usia Satpol PP Kota Semarang. Jurnal psikologi. Vol 1, no 2, p. 34 - 40 .

Ghufron. (2004). Hubungan Kontrol Diri dan Persepsi Remaja Terhadap Penerapan Disiplin Orang Tua dengan Prokrastinasi Akademik. Tabula Rasa. Vol 2. No 1.

Goleman, D. (2005). Emotional Inteligence. Jakarta : PT Gramedia Pustaka Utama.

Gracia, H. (2008). Perbedaan Agresivitas pada Anggota Beladiri Karate dan Aikido dengan Mengendalikan Kontrol Diri dan Usia. Skripsi, tidak diterbitkan. Semarang : Fakultas Psikologi Universitas Katolik Soegijapranata Semarang.

Hadi, S. (2000). Statistik Jilid I, Cetakan ke-22. Yogyakarta : Yayasan Penerbit Psikologi Universitas Gajah Mada.

Indri. (2010). (http://darknessindri.blogspot.com/2010/02/ stress-pada-tenaga-kerjasatuan.html). 
Karimi, R. \& Alipour, F. (2011). Reduce Job Stress in Organizations: Role of Locus of Control, International Journal of Business and Social Science. Vol 2 No. 18. Pg. 130-143.

Krahe, B. (2005). Perilaku Agresif. Buku panduan psikologi sosial. Yogyakarta: Pustaka Pelajar.

Kunarto, A.T. (1996). "POLISI (Harapan \& Kenyataan)". Jakarta : CV. SAHABAT

Lutfiyah. (2011). Analisis faktorfaktor yang mempengaruhi stres kerja pada polisi lalu lintas. Skripsi, tidak diterbitkan. Jakarta : Fakultas Psikologi Universitas Islam Negeri Syarif Hidayullah.

Singarimbun, M. \& Effendi, S. (1995). Metode Penelitian Survei. Edisi Revisi. Jakarta : PT Pustaka LP3ES.

Mukarromah, E. (2008). Hubungan antara Kecerdasan Emosional dengan Perilaku Agresif pada Polisi Samapta Polda Metro Jaya. Jurnal Psikologi. Tahun 2008.

Munandar, A.S. (2006). Psikologi Industri dan Organisasi. Jakarta : UI Press.

Myers, D.G. (2005). Social psychology (8). Toronto: McGraw Hill.
Nazir, M. (2009). Metode Penelitian. Bogor: Ghalia Indonesia.

Prihatini. (2007). Hubungan beban kerja dengan stress kerja perawat di tiap ruang rawat inap RSUD Sidikalang Sumatra Utara : Sekolah Pasca Sarjana USU.

Putra, A.P. (2015). Hubungan antara Self Control dengan Agresivitas Anggota Polri di Polres Sidoarjo. Skripsi, tidak diterbitkan. Surabaya : Fakultas Psikologi Universitas 17 Agustus 1945.

Rachdianti, Y. (2011). Hubungan antara Self Control dengan Intensitas Penggunaan Internet Remaja Akhir. Skripsi, tidak diterbitkan. Jakarta: Fakultas Psikologi Universitas Islam Negeri Syarif Hidayatullah Jakarta.

Sarwono, S.W. (2002). Psikologi Lingkungan. Jakarta: PT Gramedia Widiasarana Indonesia.

Sears, D.O., Freedman, J.L., Peplau, L.A. (1991). Psikologi Sosial: Jilid 2. Alih bahasa: Michael Adryanto. Jakarta: Erlangga (edisi 5).

Sugiyono. (2002). Prosedur penelitian. Jakarta : Ghalia Indonesia. 
Tangney, J.P., Baumeister, R.F., \& Boone, A.L. (2004). High self-control predicts good adjustment, less pathology, better grades, and interpersonal success. Journal of Personality, 72(2), 271-322.

Undang-undang nomor 2 Tahun 2002 tentang Kepolisian Negara Republik Indonesia.

(2012). Polisi Penembak Warga Sidoarjo. Nasional.tempo.co/read/new s/2012/06/04/o58408195/po lisi-penembak-wargasidoarjo-bantah-rekayasakasus. Diakses 10 Juli 2015.

(2017). Oknum Brimob Tembak Mahasiswa. http://www.tribunnews.com /regional/2017/03/14. Diakses 4 April 2017. 